\title{
In-situ Observation of Lyophilization Process in Environmental Scanning Electron Microscope
}

\author{
${\text { L’ubica Vetráková }{ }^{1} \text {, Vilém Neděla }{ }^{1} \text { and Jiří Runštuk }}^{1}$ \\ 1. Environmental Electron Microscopy Group, Institute of Scientific Instruments of the Czech Academy \\ of Science, Brno, Czech Republic.
}

Lyophilization (freeze-drying) is nowadays the most common formulation strategy to prepare pharmaceuticals as in the solid state chemical or physical degradation reactions are inhibited or sufficiently decelerated [1]. However, it is a very time-consuming and expensive process. Lyophilisation at elevated temperatures can be used to accelerate the cost-intensive drying step and thus reduce the overall time and cost of the process (increase in temperature of $1{ }^{\circ} \mathrm{C}$ was reported to decrease the drying time by about 13\%) [2]. Nonetheless, it is recommended to keep the product temperature just below the collapse temperature (Tc) during primary drying to avoid an undesirable collapse of a freeze-dried cake [3]. Scanning electron microscopy (SEM) is usually used to examine the resulting morphology of the freeze-dried cake and to determine the product quality [4]. However, SEM cannot be used to monitor the product structure during the lyophilisation process at the temperatures close to Tc due to difficulties with maintaining the SEM vacuum because of excessive ice sublimation. To monitor potential collapse, freeze-drying microscopy (FDM) is commonly applied [5].

Here we present dynamical in-situ monitoring of the drying step in lyophilisation of 5\% (w/w) BSA solution inside environmental scanning electron microscope (ESEM) AQUASEM II [6] under pharmaceutically relevant conditions. We observed the changes in microstructure of the protein during drying at the temperature of $-20^{\circ} \mathrm{C}$ and the pressure of $700 \mathrm{~Pa}$.

One example of the time-lapse imaging of the drying of a frozen sample is illustrated in Figure 1. The very start of the drying (smooth ice surface) was not recorded due to partial sublimation of ice while the ESEM chamber was being evacuated. In the beginning of observation shallow grooves were visible on the frozen surface (Figure 1a). The grooves became deeper and wider due to ice sublimation (Figure 1b). Freeze-dried protein appeared to be arranged in cross-linked layers that eventually started to tear apart (Figure 1c) and a sheet-like structure was formed (Figure 1d). We did not observe any collapse during the drying as the temperature used in our experiments was below Tc $\left(-5{ }^{\circ} \mathrm{C}\right.$ for $5 \% \mathrm{BSA}$ [5]). However, it was shown previously that ESEM can be also used to determine Tc in a manner similar to FDM [7]. Therefore, ESEM can be used for real-time monitoring of the formulation microstructure during drying, the presence of collapse, and the structure of the resulting freeze-dried cake, all in one experiment without the need for special sample preparation, e.g. conductive coating. Even though electron microscopy is predominantly a surface-sensitive method, micromanipulators can be used to rotate or bisect the sample directly in the ESEM chamber so the inner structure would also be visible without the sample being exposed to atmospheric moisture. However, from the microscopy alone it is not evident if the observed mechanical stress during freeze-drying has negative effects on the relevant properties of the formulation. All requests for poster presentations will be honoured [8].

\section{References:}

[1] JC Kasper et al, Eur. J. Pharm. Biopharm. 78 (2011), p. 248. 
[2] M Pikal, J. Parenter. Sci. Technol. 39 (1985), p. 115.

[3] JC Kasper et al, Eur. J. Pharm. Biopharm. 85 (2013), p. 162.

[4] J Liu, Pharm. Dev. Technol. 11 (2006), p. 3.

[5] E Meister et al, J. Pharm. Sci. 98 (2009), p. 3072.

[6] X Yang et al, Atmos. Chem. Phys. 17 (2017), p. 6291.

[7] P Meredith et al, J. Pharm. Sci. 85 (1996), p. 631.

[8] The research was supported by the MEYS CR (LO1212), its infrastructure by the MEYS CR and the EC (CZ.1.05/2.1.00/01.0017) and by the CAS (RVO: 68081731).

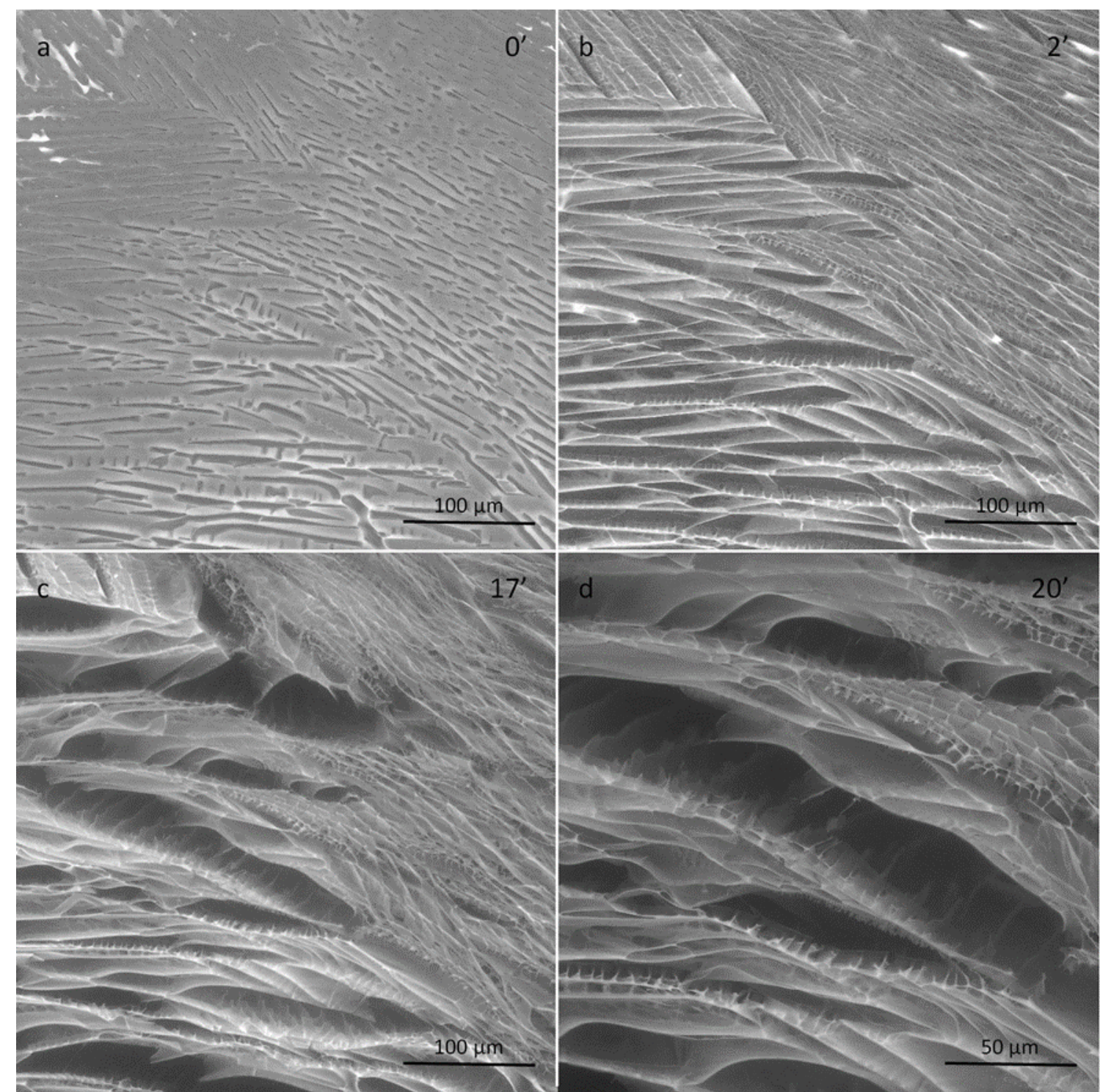

Figure 1. Time-lapse imaging of the drying of frozen 5\% BSA solution. The elapsed time after the chamber evacuation is indicated in the panels. Due to minor ice sublimation during the chamber evacuation, the grooves on the sur face of the sample are present in the beginning of the imaging. 